\title{
Married women's autonomy and associated factors on modern contraceptive use in Adwa Town, Northern Ethiopia
}

\author{
Mussie Alemayehu ${ }^{1}$, Kiday Hailesellasie ${ }^{1}$, Gebrezgabiher Biruh ${ }^{2}$, Gebremedhin Gebrezgabiher ${ }^{3,}$, \\ Fitwi Tinsae $^{3}$, Abadi Kidanemariam ${ }^{4}$, Yemane Brhane ${ }^{4}$
}

${ }^{1}$ Department of Public Health, Mekelle University, Mekelle, Ethiopia

${ }^{2}$ Department of Nursing, Areaya Kahsu College of Health Sciences, Axum, Ethiopia

${ }^{3}$ Department of Nursing, Dr. Tewolde College of Health Sciences, Mekelle, Ethiopia

${ }^{4}$ Department of Nursing, Mekelle University, Mekelle, Ethiopia

\section{Email address:}

abadik012@gmail.com (A. Kidanemariam), messi.fit@gmail.com (F. Tinsae),gbamsc2002@gmail.com(G. Biruh), gebremedhingebretsad@gmail.com (G. Gebrezgabiher), hkiday@gmail.com (K. Hailesellasie), mossalex75@gmail.com (M. Alemayehu),yemaneberhane12@gmail.com (Y. Brhane)

\section{To cite this article:}

Mussie Alemayehu, Kiday Hailesellasie, Gebrezgabiher Biruh, Gebremedhin Gebrezgabiher, Fitwi Tinsae, Abadi Kidanemariam, Yemane Brhane. Married Women's Autonomy and Associated Factors on Modern Contraceptive Use in Adwa Town, Northern Ethiopia. Science Journal of Public Health. Vol. 2, No. 4, 2014, pp. 297-304. doi: 10.11648/j.sjph.20140204.19

\begin{abstract}
Background: Women's autonomy of modern contraceptive use means that those women taking, not taking or even stopping using modern contraceptive by their own decision only. Women's autonomy in health care decision-making is extremely important for better maternal and child health outcomes. Fertility and contraceptive use in developing countries are associated with various markers of socioeconomic status, most prominent of which is women's autonomy. Women in developing countries, including Ethiopia are either under collective decision making with their partners or completely rely on the male partner's decision on issues that affect their contraceptive use. The objective of this study was to assess the prevalence of married women's autonomy and associated factors for modern contraceptive use in Adwa town, Tigray Region, North Ethiopia. Methods: A community based cross-sectional study design was conducted from September 7-18, 2012. Three hundred seventy married women were selected using simple random sampling technique. Data were entered, cleaned and analyzed by using statistical package for social sciences (SPSS) Version 20.0 (SPSS Illinois, Chicago). Binary descriptive statistics and multiple variable regressions were done. Results: In this study from a total of 370 respondents, 133(35.9\%) reported that they had autonomy on modern contraceptive use. Educational status of the women was a strong significant predictor in the women's autonomy on modern contraceptive use. Moreover, mothers did not know their husband's attitude towards contraception use ( $\mathrm{AOR}=4.34,95 \% \mathrm{CI}: 1.54,12.2)$, discussed with their husband about the number of children $(\mathrm{AOR}=0.48,95 \% \mathrm{CI}: 0.24,0.96)$, born two and less children ( $\mathrm{AOR}=0.14,95 \% \mathrm{CI}$ : 0.03, 0.66) and decides their future number of children by themselves $(\mathrm{AOR}=34.8,95 \% \mathrm{CI}: 12.14,99.7)$ and by joint decision $(\mathrm{AOR}=2.5,95 \%$ CI:1.04,6.0) were more likely autonomous on modern contraceptive use. Conclusions: The autonomy of married women on modern contraceptive use in this study was low. Having better educational attainment has an input on increase women's autonomy on modern contraceptive use. Women who had power of deciding on the number of child present, number child will have in the future, the number of children born and husband's attitude toward contraceptive use could influence on autonomy of women on modern contraceptive use.
\end{abstract}

Keywords: Women, Autonomy, Adwa, Tigray

\section{Introduction}

Women's autonomy in health care decision-making is extremely important for better maternal and child health outcomes. Gender-based power inequalities can restrict open communication between partners about reproductive health decisions as well as women's access to reproductive health services. This in turn can contribute to poor health 
outcomes [1]. Throughout the world, women constitute the poor, underemployed and socially and economically disadvantaged. There is recognition that virtually no society provides women with equal status with men and has a lower social status and autonomy than men [2].

Contraceptive uses in developing countries are associated with various indicators of socioeconomic status and cultural factors, and the most prominent of which is women's autonomy. The ability of women to make decisions that affect the circumstances of their own lives is an essential aspect of empowerment [2]. Many researchers have been conducting an effort to uncover obstacles of family planning acceptance and continuation usage. However, historically demographic researches have been focused on women and ignored the role of men in couple's fertility decision-making, especially in Africa, where men are the primary decision-makers of most family matters [3].

Different study in globally argues that female autonomy is multi-dimensional, meaning that different aspects of female autonomy, such as financial autonomy and female mobility may affect contraceptive use. Despite this, efforts to examine the relationship between female autonomy and fertility outcomes, it is still unclear which aspects of female autonomy affect contraceptive use and to what degree $[4,5]$.

Ethiopian men are dominant decision-makers in most family matters, including fertility and family planning. Women are either under collective decision-making with their partners or completely rely on the male partner's decision on issues that affect their reproductive health need [3]. Improving the educational status of women has a significant contribution on women's autonomy in use, not use and stopping of using the contraceptive, increases socioeconomic status and enhances husband-wife communication and decision making [6].

There is no study that documented on assessing factors associated with women's autonomy on modern contraceptive utilization in the Tigray region. This study was to assess the magnitude and factors associated married women's autonomy on modern contraceptive among married women in Adwa town, Tigray region, North Ethiopia.

\section{Methods}

\subsection{Study area and Setting}

A community based cross-sectional study was conducted from September 7-18, 2012. The study was done in Adwa town, Tigray region, in the Northern part of Ethiopia. The total population of the area was 60,748 , with 27,454 males and 33,294 females [7]. Tigre is the dominant ethnic group in Adwa. In Adwa town the administration is divided into Kebele (the lowest administrative unit).

\subsection{Sampling}

The sample size was determined using a formula for estimation of single population proportion with the assumption of $95 \%$ confidence level, the margin of error of $5 \%$ and the expected prevalence of married women's autonomy on contraceptive use in South Nation and Nationality people (SNNP) of Ethiopia was (0.64) [8]. To compensate the non-response rate, $10 \%$ of the determined sample was added up to. The total number of married women in Adwa town was around 7,338 women. So correction formula was employed and finally 372 women's were employed.

Administratively, the town is divided in to 5 kebelles; namely Alula, Debrchi, Mebale, Hayelom and Abnet [7]. All kebeles were included in the study area. The sample size was proportional distributed to all kebeles based on the number of married women. The town contains 13,365 and 7,338 reproductive age groups and married women of reproductive age group, respectively. The sampling frame of the married women was obtained from urban health extension workers. The study subjects were selected by simple random sampling technique.

\subsection{Method of Data Collection}

The data were collected using structured interviewer administered questionnaires and constitute information on socio demographic and economic characteristics, reproductive history, women's autonomy on modern contraceptive and related factors. The questionnaires were adapted from different studies considering the local situation of the study area [3, 8,13]. Questionnaires were prepared first in English then translated into the local language (Tigrigna) for data collection by language experts. To check whether the translation was consistent with the English version the questionnaire were back translated to English by another language expert. Before the actual data collection, the questionnaire was pre-tested at 5\% (35 women) in Aby-adi town which is $60 \mathrm{~km}$ north from Adwa. Based on the pretest, the time needed for the complete interview and the number of data collectors in need was estimated. The principal investigator trained five clinical nurses as data collectors and two Bsc nurses as supervisors for two consecutive days on objective, data collection tools and interview techniques. The interview was conducted in a place where the woman feels free to express her feelings and ideas. Moreover, in occasions where the sampled women were not accessed for absence, up to three attempts were being endeavored for interviewing to lessen the non response rate.

\subsection{Measurement}

Women's autonomy of modern contraceptive use: Those women taking, not taking or stopping modern contraceptive by their own decision only. Women's don't autonomy of modern contraceptive use those women taking, not taking or stopping modern contraceptive by joint and/or husband decision only. To measure the degree of women's autonomy on modern contraceptive use three questions were used to construct composite score and these 
questioner were decision on current contraceptive use, decision on stopping contraceptive use and decision on not use contraceptive "Having autonomy" - those who scored above the mean on women autonomy on modern contraceptive utilization items and "Not having autonomy" - those who scored mean or below mean to women autonomy on modern contraceptive utilization. Household decision making; to measure the degree of women's involvement in domestic decision-making five questions were used to construct composite score: "Having domestic autonomy" - those who scored above the mean on household decision making items and "Not having decision-making" - those who scored the mean or below the mean to household decision making items. Financial autonomy: to measure women's financial autonomy three questions were used to construct composite score: "Better financial autonomy"- those who scored above the mean on financial autonomy items and "low financial autonomy" those who scored the mean or below mean to financial autonomy items. Movement autonomy: to measure women's freedom movement (the ability to visit friends, health facility) five questions were used to construct composite score: "Better freedom movement"- those who scored above mean on movement autonomy items and "low freedom autonomy" - those who scored mean or below mean to movement autonomy items. Attitude on Gender Roles: To measure women's attitude on gender equitable six questions was used to construct composite score: "Better gender equitable attitude"- those who scored above the mean on attitude on gender roles items and "low gender equitable attitude" - those who scored the mean or below mean to attitude on gender roles items.

\subsection{Data Analysis}

The quantitative data were entered, cleaned and analyzed by using statistical package for social sciences (SPSS) version 20.0 (SPSS Illinois, Chicago). First descriptive analyses were carried out for each of the variables. Second, bivariate analyses were done for the independent variables with the outcome variable to select candidate variables for the multivariable logistic regression analyses. Finally, variables which showed significant association with the dependent variable in the bivariate analysis were entered into a multivariate logistic regression model to identify their independent effects. Moreover, Multicolinarity test also done to assess the interaction among the independent variables.

\subsection{Ethical Considerations}

The study was approved by the Mekelle University College of health ethical review board. The importance of the study was explained to the participant of the study. For this a one page consent letter was attached to the cover page of each questionnaire and it was explained to study participants that participation is voluntary and confidentiality and private information was protected. The right of the respondent to withdraw from the interview or not to participate was respected. The information collected from the study subjects was kept confidential and it was used only for study purpose.

\section{Results}

Table 1. Socio-demographic and economic characteristics of married women's and their husband in Adwa town, Tigray, Northern Ethiopia, 2012

\begin{tabular}{|c|c|c|}
\hline Variables & Number & Percent \\
\hline \multicolumn{3}{|l|}{ Age of women $(n=370)$} \\
\hline $15-19$ & 9 & 2.4 \\
\hline $20-24$ & 145 & 39.2 \\
\hline $25-29$ & 95 & 25.7 \\
\hline $30-34$ & 60 & 16.2 \\
\hline $35-39$ & 36 & 9.7 \\
\hline$\geq 40$ & 25 & 6.8 \\
\hline \multicolumn{3}{|l|}{ Age of husband $(n=370)$} \\
\hline$<30$ & 116 & 31.4 \\
\hline $30-44$ & 182 & 49.2 \\
\hline$\geq 45$ & 72 & 19.5 \\
\hline \multicolumn{3}{|l|}{ Ethnicity $(\mathrm{n}=370)$} \\
\hline Tigre & 363 & 98.1 \\
\hline Amhara & 7 & 1.9 \\
\hline \multicolumn{3}{|l|}{ Religion $(n=370)$} \\
\hline Orthodox & 322 & 87 \\
\hline Muslim & 41 & 11.1 \\
\hline Protestant & 7 & 1.9 \\
\hline \multicolumn{3}{|c|}{ Educational status of women $(n=370)$} \\
\hline No education & 49 & 13.2 \\
\hline Able to read and write & 10 & 2.7 \\
\hline Primary(1-8 grade) school & 102 & 27.6 \\
\hline Secondary school & 159 & 43 \\
\hline Higher education & 50 & 13.5 \\
\hline \multicolumn{3}{|c|}{ Educational status of husband $(n=370)$} \\
\hline No education & 47 & 12.7 \\
\hline Able to read and write & 28 & 7.6 \\
\hline Primary(1-8 grade) school & 80 & 21.6 \\
\hline Secondary school & 112 & 30.3 \\
\hline Higher education & 103 & 27.8 \\
\hline \multicolumn{3}{|c|}{ Occupation of women $(n=370)$} \\
\hline Un employed & 226 & 61.1 \\
\hline Government employer & 77 & 20.8 \\
\hline Private employed & 67 & 18.1 \\
\hline \multicolumn{3}{|c|}{ Occupation of husband $(n=370)$} \\
\hline Un employed & 18 & 4.9 \\
\hline Government employer & 130 & 35.1 \\
\hline Private employed & 222 & 60.0 \\
\hline \multicolumn{3}{|c|}{ Monthly family income $(n=370)$} \\
\hline$\leq 27.8 \$$ & 70 & $18.9 \%$ \\
\hline $27.8-83.3 \$$ & 189 & $51.1 \%$ \\
\hline $83.4-138.8 \$$ & 59 & $15.9 \%$ \\
\hline$>138.8 \$$ & 52 & $14.1 \%$ \\
\hline
\end{tabular}

$1 \$=18$ Ethiopian Birr

A total of 372 married women were participating in this study and making the response rate of $99.5 \%$. The mean age of the participants were $27.82(\mathrm{SD}=5.6)$ years. The majorities, were Orthodox Christians 322(87\%), had attended secondary school 159(43\%) and unemployed 226 $(61.1 \%)$ in occupational status. Pertaining to the husband characteristics $182(49.2 \%), 112(30.3 \%)$ and $222(60 \%)$ were between the age of 30-34, completed secondary 
school and private employed in occupational status respectively. One hundred eighty nine $(51.1 \%)$ of the respondent family incomes were ranging between 27.883.3 \$ [Table 1].

One hundred forty $(36.2 \%)$ of the women was married at the age of below eighteen. Almost all 348(94.1\%) of the respondents were gave birth, out of this 201(57.5\%) had two and less birth. Majority $129(34.9 \%)$ of the married women had a duration of living together for 5-9 years. Surprisingly, all the participants wanted to have children for the future, out of this $141(38.1 \%$ ) had a desire of 3-4 children [Table 2].

Table 2. Reproductive history of married women's in Adwa town, Tigray, Northern Ethiopia, 2012

\begin{tabular}{lcc}
\hline Variables & Number & Percent \\
\hline Age at first marriage $(\mathrm{n}=370)$ & & \\
$<18$ & 134 & 36.2 \\
$\geq 18$ & 236 & 63.8 \\
Do you gave birth $(\mathrm{n}=370)$ & & \\
Yes & 348 & 94.1 \\
No & 22 & 5.9 \\
Number of child birth(n=348) & & \\
$\leq 2$ & 201 & 57.7 \\
$3-4$ & 105 & 30 \\
$\geq 5$ & 42 & 12.3 \\
Duration of living together in years $(\mathrm{n}=370)$ & \\
$\leq 2$ & 34 & 9.2 \\
$3-4$ & 65 & 17.6 \\
$5-9$ & 129 & 34.9 \\
$\geq 10$ & 142 & 38.3 \\
Desire number of children $(\mathrm{n}=370)$ & & \\
$\leq 2$ & 145 & 39.2 \\
$3-4$ & 141 & 38.1 \\
$\geq 5$ & 84 & 22.7 \\
\hline
\end{tabular}

In this study, 305(82.4\%) and 234(76.7\%) of the married women have been ever and current use modern contraceptive, respectively. Injectables were the most common type of contraceptive used by the married women $147(62.8 \%)$ currently. On the subject of women's autonomy in modern contraceptive utilization, woman's decision was made for use of contraceptive currently 80 (34.2\%), stopping use of contraceptive 29(40.8\%) and not using of contraceptive $24(36.9 \%)$. The composite measure of married women's autonomy shows that $133(35.9 \%)$ of the participants had autonomy on contraceptive use, whereas the remaining, 237(64.1\%) hadn't autonomy. Surprisingly, 219(59.2\%) of the women had a joint decision on deciding the number of children. A majority, $276(74.6 \%), 295(79.7 \%)$ and $255(68.9 \%)$ of the participant discussed on the number of children they want to have, ever discussed about family planning and don't face opposition from their husband for using contraceptive, respectively [Table 3]. As regards to the financial decision making of the participants, 214(57.8\%), 249(67.3\%) and 29 $(80.5 \%)$ of the family's main source of income was the husband, the women's do not earn their own monthly income and don't have their own saving scheme currently, respectively.
Table 3. Type of contraceptive use married women on modern contraceptive use, in Adwa town, Tigray, Northern Ethiopia, 2012

\begin{tabular}{|c|c|c|}
\hline Variables & Number & Percent \\
\hline \multicolumn{3}{|c|}{ Ever use modern contraceptive $(n=234)$} \\
\hline Yes & 305 & $82.4 \%$ \\
\hline No & 65 & $17.6 \%$ \\
\hline \multicolumn{3}{|c|}{ Currently use modern contraceptive $(n=370)$} \\
\hline Yes & 234 & $76.7 \%$ \\
\hline No & 71 & $23.3 \%$ \\
\hline \multicolumn{3}{|c|}{ Types of modern contraceptive $(n=234)$} \\
\hline Pills & 20 & $8.5 \%$ \\
\hline Intrauterine device (IUCD) & 15 & $6.4 \%$ \\
\hline Inject able (Depo-Provera) & 147 & $62.8 \%$ \\
\hline emergency contraceptive & 8 & $3.4 \%$ \\
\hline Norplant & 41 & $17.5 \%$ \\
\hline Others & 3 & $1.3 \%$ \\
\hline \multicolumn{3}{|c|}{ Decision on current contraceptive use $(\mathrm{n}=234)$} \\
\hline Women decision & 80 & $34.2 \%$ \\
\hline Women and husband decision & 125 & $53.4 \%$ \\
\hline Husband decision & 29 & $12.4 \%$ \\
\hline \multicolumn{3}{|c|}{ Decision on stopping contraceptive use $(n=71)$} \\
\hline Women decision & 29 & $40.8 \%$ \\
\hline Women and husband decision & 22 & $31 \%$ \\
\hline Husband decision & 20 & $28.2 \%$ \\
\hline \multicolumn{3}{|c|}{ Decision on not use contraceptive $(n=71)$} \\
\hline Women decision & 24 & $36.9 \%$ \\
\hline Women and husband decision & 25 & $38.5 \%$ \\
\hline Husband decision & 16 & $24.6 \%$ \\
\hline \multicolumn{3}{|c|}{ Decides the number of children $(n=370)$} \\
\hline Your own decision & 73 & 19.7 \\
\hline Yours and husband decision & 219 & 59.2 \\
\hline Your husband decision & 78 & 21.1 \\
\hline \multicolumn{3}{|c|}{ Discussed how many children they wanted $(n=370)$} \\
\hline Yes & 276 & 74.6 \\
\hline No & 94 & 25.4 \\
\hline \multicolumn{3}{|c|}{ Ever discussed About family planning $(n=370)$} \\
\hline Yes & 295 & 79.7 \\
\hline No & 75 & 20.3 \\
\hline \multicolumn{3}{|c|}{ Opposition from your husband for using Contraceptive methods $(n=370)$} \\
\hline Yes & 115 & 31.1 \\
\hline No & 255 & 68.9 \\
\hline
\end{tabular}

Beside this, information related to the household decision making, a joint decision was made by the couple for buying of clothing to the family 229(61.9\%), buying large household goods 242 (65.4) and seek treatment for ill child 272(73.5\%). Moreover, a joint decision was made to work outside of the home 197(53.2) and to buy materials needed for school children 260(70.3\%). Pertaining to the women's autonomy on movement, majority 232(62.7\%) and $293(79.2 \%)$ of the women need permission from husband to visit local market and to go to outside of her home for certain activities, respectively. Furthermore, women need permission of her husband to visit her friends $260(70.3 \%)$ and visit husband relatives 265 (71.6\%).

Information regarding to the attitude of gender role, 323 $(87.3 \%), 256(69.2 \%)$ and $239(64.6 \%)$ of the women were disagreeing for the statement of wife shouldn't have ownership and authority on the family wealth, a husband 
should decide on the number of children in the family and husband should decide the expenditure of the family, respectively. In addition to this, out of the total 183 (49.5\%), 301(81.4\%) and 283(76.5\%) women's were agree that woman's should work the domestic activity, their husband had positive attitude towards the current use of contraceptive and a woman needs her husband's permission to use any contraceptive method, respectively [Table 4].

Table 4. Factors related to women's autonomy on modern contraceptive use, in Adwa town, Tigray, Northern Ethiopia, 2012

\begin{tabular}{|c|c|c|}
\hline Variables & Number & Percent \\
\hline \multicolumn{3}{|c|}{ Financial decision making $(n=370)$} \\
\hline \multicolumn{3}{|c|}{ Family's main source of income } \\
\hline Husband & 214 & 57.8 \\
\hline $\mathrm{Me}$ & 6 & 1.6 \\
\hline Both & 150 & 40.5 \\
\hline \multicolumn{3}{|c|}{ Earn your own monthly income } \\
\hline Yes & 121 & 32.7 \\
\hline No & 249 & 67.3 \\
\hline \multicolumn{3}{|c|}{ Currently saving scheme by your self } \\
\hline Yes & 72 & 19.5 \\
\hline No & 298 & 80.5 \\
\hline \multicolumn{3}{|c|}{ House hold decision making $(n=370)$} \\
\hline \multicolumn{3}{|c|}{ Decision to buy clothes for you and the family } \\
\hline $\mathrm{Me}$ & 43 & 11.6 \\
\hline Husband & 98 & 26.5 \\
\hline Both & 229 & 61.9 \\
\hline \multicolumn{3}{|c|}{ Decision to buy large household activities } \\
\hline $\mathrm{Me}$ & 21 & 5.7 \\
\hline Husband & 107 & 28.9 \\
\hline Both & 242 & 65.4 \\
\hline \multicolumn{3}{|c|}{ Decision to seek treatment for ill child } \\
\hline $\mathrm{Me}$ & 45 & 12.2 \\
\hline Husband & 53 & 14.3 \\
\hline Both & 272 & 73.5 \\
\hline \multicolumn{3}{|c|}{ Decision to work outside home } \\
\hline $\mathrm{Me}$ & 49 & 13.2 \\
\hline Husband & 124 & 33.5 \\
\hline Both & 197 & 53.2 \\
\hline \multicolumn{3}{|c|}{ Decision to buy materials needed for school children } \\
\hline $\mathrm{Me}$ & 23 & 6.2 \\
\hline Husband & 87 & 23.5 \\
\hline Both & 260 & 70.3 \\
\hline \multicolumn{3}{|c|}{ Movement autonomy $(n=370)$} \\
\hline \multicolumn{3}{|c|}{ Need Permission from husband to go for a local market } \\
\hline Yes & 232 & 62.7 \\
\hline No & 138 & 37.3 \\
\hline \multicolumn{3}{|c|}{ Need permission from husband to go outside the home } \\
\hline Yes & 293 & 79.2 \\
\hline No & 77 & 20.8 \\
\hline \multicolumn{3}{|c|}{ Need permission from husband to visit friends } \\
\hline Yes & 260 & 70.3 \\
\hline No & 110 & 29.7 \\
\hline \multicolumn{3}{|c|}{ Need permission from husband to visit husband relatives } \\
\hline Yes & 280 & 75.7 \\
\hline No & 90 & 24.3 \\
\hline \multicolumn{3}{|c|}{ Need permission from husband to visit health center } \\
\hline Yes & 265 & 71.6 \\
\hline No & 105 & 28.4 \\
\hline
\end{tabular}

Continued table on description of factors related to women's autonomy on modern contraceptive use, in Adwa town, Tigray, Northern Ethiopia, 2012

\begin{tabular}{lcc}
\hline Variables & Number & Percent \\
\hline Attitude on Gender Roles (n=370) & & \\
Woman's job to take care of the domestic activity & for her family \\
Agree & 183 & 49.5 \\
Neutral & 8 & 2.2 \\
Disagree & 179 & 48.4 \\
Wife shouldn't have ownership and authority on the family wealth \\
Agree & 36 & 9.7 \\
Neutral & 11 & 3.0 \\
Disagree & 323 & 87.3 \\
Husband should decide the number of children in the family \\
Agree & 102 & 27.6 \\
Neutral & 12 & 3.2 \\
Disagree & 256 & 69.2 \\
You husband's attitude towards current use of contraceptive \\
Agree & 301 & 81.4 \\
Neutral & 33 & 8.9 \\
Disagree & 36 & 9.7 \\
A woman needs her husband's permission to use any contraceptive \\
method & \multicolumn{3}{|c}{} \\
Agree & 283 & 76.5 \\
Neutral & 13 & 3.5 \\
Disagree & 74 & 20.0 \\
Husband should decide the expenditure of the family & \\
Agree & 126 & 34.1 \\
Neutral & 5 & 1.4 \\
Disagree & 239 & 64.6 \\
\hline & \multicolumn{2}{c}{} \\
\hline
\end{tabular}

The composite measure of women's autonomy factors to modern contraceptive use indicates that, 203(54.3\%) of the married women had low gender equitable attitude, 228 $(61.6 \%)$ had low freedom autonomy and 274 (73.5\%) had low financial decision making role. However, 226 (61.1\%) of the married women had better financial autonomy [Figure 1].

The results of multivariable logistic regression analysis showed that women who had attended primary school, secondary school and higher education were 8, 22 and 22 times higher autonomy of modern contraceptive use when compared with those who had no education $[(\mathrm{AOR}=8.1,95 \%$ CI: 2.09,31.44), (AOR=22. 1,95\% CI: 5.41,90.12) and ( $\mathrm{AOR}=21.7,95 \% \mathrm{CI}: 4.47,105.73)]$ respectively. Mothers who born two and less children were $86 \%$ times less likely autonomy of modern contraceptive use than those women who born five and above children $(\mathrm{AOR}=0.14,95 \% \mathrm{CI}$ : $0.03,0.66)$. Mothers who discussed with their husband about the number of child were 52\% less likely autonomy on modern contraceptive use than those women who were not discussed $\mathrm{AOR}=0.48,95 \% \mathrm{CI}: 0.24,0.96$ ). Mothers who decides their future number of children by themselves and had joint decision with their husband were 34 and 3 times more likely autonomy on modern contraceptive use as compare with those women who decided their modern contraceptive use by their husband (AOR $=34.8,95 \%$ $\mathrm{CI}: 12.14,99.7) \quad$ and $\quad(\mathrm{AOR}=2.5,95 \% \quad \mathrm{CI}: 1.04,6.0)$ 
respectively. Mothers who did not know their husband's attitude towards contraception use were 4 times more likely autonomy on modern contraceptive use as compared with those who knew their husband attitude $(\mathrm{AOR}=4.34,95 \%$ CI:1.54,12.2)[Table 5].

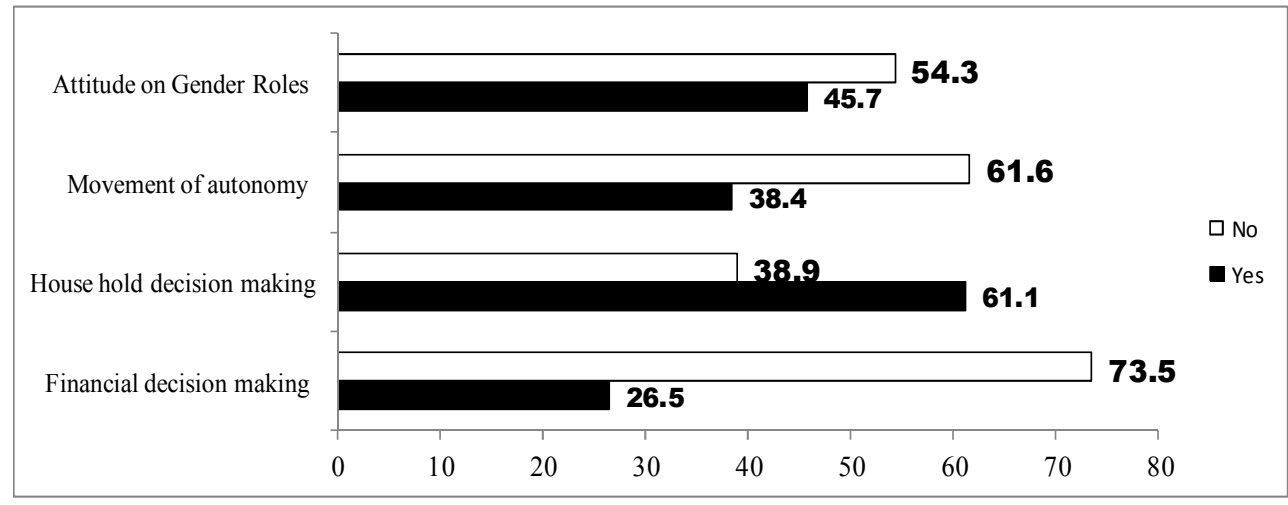

Figure 1. Overall description of factors on women's autonomy on modern contraceptive use, in Adwa town, Tigray, North Ethiopia, 2012

Table 5. Predictors of married women's autonomy on modern contraceptive use in Adwa town, Tigray, Northern Ethiopia, 2012

\begin{tabular}{|c|c|c|c|c|}
\hline \multirow[t]{2}{*}{ Variables(n=370) } & \multicolumn{2}{|c|}{$\begin{array}{l}\text { Autonomy on modern } \\
\text { contraceptive use }\end{array}$} & \multicolumn{2}{|c|}{ Odds ratio(95\%.CI) } \\
\hline & No $(\%)$ & Yes $(\%)$ & COR & $\mathrm{AOR}$ \\
\hline \multicolumn{5}{|l|}{ Educational status of women } \\
\hline No education & $44(18.6)$ & $5(3.8)$ & 1.0 & 1.0 \\
\hline Able to read and write & $6(2.5)$ & $4(3.0$ & $5.8(1.22,28.12)$ & $6.0(0.74,49.55)$ \\
\hline Primary (1-8 grade) & $67(28.3)$ & $35(26.3)$ & $4.5(1.67,12.63)$ & $8.1(2.09,31.44)$ \\
\hline Secondary complete & $88(37.1)$ & $71(53.4)$ & $7.1(2.67,18.85)$ & $22.1(5.41,90.12)$ \\
\hline Higher education & $32(13.5)$ & $18(13.5)$ & $4.9(1.16,14.72)$ & $21.7(4.47,105.7)$ \\
\hline \multicolumn{5}{|l|}{ Number of child born } \\
\hline$\leq 2$ & $139(58.6)$ & $62(46.6)$ & $0.4(0.20,0.79)$ & $0.14(0.03,0.66)$ \\
\hline $3-4$ & $62(26.2)$ & $43(32.3)$ & $0.6(0.30,1.29)$ & $0.4(0.10,1.31)$ \\
\hline$\geq 5$ & $20(8.4)$ & $22(16.5)$ & 1.0 & 1.0 \\
\hline \multicolumn{5}{|c|}{ Decides the number of children they will have } \\
\hline Your own decision & $14(5.9)$ & $59(44.4)$ & $25.6(10.82,60.8)$ & $34.8(12.14,99.7)$ \\
\hline Yours and husband decision & $156(65.8)$ & $63(47.4)$ & $2.5(1.22,4.96)$ & $2.5(1.04,6.0)$ \\
\hline Your husband decision only & $67(28.3)$ & $11(8.3)$ & 1.0 & 1.0 \\
\hline \multicolumn{5}{|c|}{ Discussed number of children will have } \\
\hline No & $52(21.9)$ & $42(31.6)$ & 1.0 & 1.0 \\
\hline Yes & $185(78.1)$ & $91(68.4)$ & $0.6(0.37,0.98)$ & $0.5(0.24,0.96)$ \\
\hline \multicolumn{5}{|c|}{ Husband's attitude towards contraceptive use } \\
\hline Support & 204(86.1) & 97(72.9) & 1.0 & 1.0 \\
\hline Don't know & $12(5.1)$ & $21(15.8)$ & $3.6(1.74,7.78)$ & $4.3(1.54,12.2)$ \\
\hline Oppose & $21(8.9)$ & $15(11.3)$ & $1.5(0.74,3.04)$ & $1.4(0.53,3.90)$ \\
\hline
\end{tabular}

\section{Discussion}

The prevalence of women's autonomy on modern contraceptive in this study was $35.9 \%$. Mothers did not know their husband's attitude towards contraception use, educational status, having discussion with husband about the number of child, born two and less children, decides their future number of children by themselves and by joint decision were significant predictors of women's autonomous on modern contraceptive use.

In this study $35.9 \%$ of the women had autonomy on modern contraceptive use and it was quite similar with the study done in Honduras 31\% [9]. However, this finding was higher than the study conducted in Malawi which was $17.8 \%$ [10]. This might be due to the difference in the socioeconomic status of the married women and the nature of the study area. Moreover, the finding of this study was a lower than the study conducted in Tercha woreda which was $64 \%$ [8]. The possible reason might be due to the difference of the educational status that means in this study there is high number of illiterate women's.

Finding from this study shows that, $46.5 \%$ autonomy of modern contraceptive use was made jointly (women and husband) decision. This is similar to the study done in Honduras (52\%), Egypt (60.4\%) and EDHS 2000 (53.4\%) $[9,12,13]$. Beside this, $65(17.6 \%)$ women's to use modern contraceptive currently was decided by their husband and this finding was lower than the finding of Malawi which was $63.5 \%$ and Oman $50 \%[10,11]$. The reason for this could be due to increase women's empowerment and increase men's knowledge on the right of reproductive 
health of women in Malawi and Oman and difference in cultural factor.

In this study the decision making in current use of modern contraceptive by women and joint decision was $34.2 \%$ and $12.4 \%$, respectively, this is comparable to finding of EDHS 2000 in Tigray region, which was (28.4\%) for women and (7.2\%) for husband [13]. Moreover, joint decision made about the current modern contraceptive use (53.4\%), was similar to the finding of a study done in Egypt (60.4\%) and EDHS 2000 in Tigray $(63.3 \%)[12,13]$.

In this study the financial related decision making of women was $26.5 \%$, this study was quite similar to the study done in Jimma (30.1\%) and Malawi $(28.8 \%)[3,10]$. However, this study indicates that $61.1 \%$ of women had power in deciding on household activities; this study was higher than the study done in Jimma town 20.8\% [3]. This might be due to a time gap in the study period and it is obvious nowadays there might be exposure to different media. However, this finding was lower as compared with study done in Zimbabwe 89.9 \% [14]. This reason might be due to difference in socioeconomic and cultural factors.

Education status has a significant contribution on women's autonomy in deciding modern contraceptive use This study revealed that women who had complete primary, secondary and higher education were 8, 22 and 22 times higher autonomy on modern contraceptive use when compare with those who were illiterate, respectively. In this finding the educational status of the women was very strong statistical significance with autonomy of modern contraceptive use. This finding also consistent with studies done in Honduras and Zimbabwe $[9,14]$ but different from the study conducted in Tercha woreda [8]. This might be due to difference in socio demography characteristics of the married women which indicates that a woman in Tercha woreda had lower educational status compared with the study area.

Mothers who decide their future number of children by themselves and joint decision with their husband were 34 and 3 more likely autonomy of modern contraceptive use as compared to those women who decided the modern contraceptive use by their husband, respectively. This finding was similar to the study conducted in Tercha woreda and Zimbabwe [8, 14]. This indicates that if there is women autonomy or joint decision in the couple there might be an increase on discussing in contraceptive issue which in-turn rose contraceptive utilization.

In this study, the desire for having fewer children was a negative effect on the decision making of modern contraceptive use. This is in line with a study done in Honduras -[9]-depicted that as women have more children, male centered decision shown reduction and this finding also congruent with the study done in Tercha woreda [8]. But this finding was contradicted with the study in Zimbabwe [14] this could be due to difference in study setting and time between these two studies.

Having a gender equitable attitude among couples have a contribution for the utilization of modern contraceptive.
The finding of this study indicates that mothers who did not know their husband's attitude towards contraception use were 4 times more likely autonomy of modern contraceptive use as compared with their counterparts. This is in line with a study done in Tercha woreda [8]. Moreover, mothers who discussed about the number of children will have an association with women's autonomy on modern contraceptive use.

In this study domestic decision-making were not predictors of modern contraceptive user autonomy. This finding was congruent with a study done in Egypt and Zimbabwe [12, 14]. Beside the above, financial decisions and movement autonomy variables were not statistical significance of autonomy of modern contraceptive use. This finding was congruent with the study conducted in Egypt [12]. The study suffers from the usual limitation of a cross sectional study. The knowledge and attitude towards women's autonomy towards modern contraceptive among men and its influence on their wives were not addressed through this study. The study also did not discover any information from the service provider side of women's autonomy towards modern contraceptive. In addition, the monthly income collected in this study might not reflect the truth. However, the study team had made an effort dig out possible information and to make the interview as private as possible to minimize such biases.

\section{Conclusion}

The autonomy of married women on modern contraceptive use in this study was low. Having better educational attainment has an input on increase women's autonomy on modern contraceptive use. Women who had power of deciding on the number of child present, number child will have in the future, the number of children born and husband's attitude toward contraceptive use could influence on autonomy of women on modern contraceptive use.

\section{Acknowledgment}

We would like to thank Mekelle University, College of Health Sciences for funding this research. Our gratitude goes to supervisors, data collectors, respondent who participated in this study and Adwa town administrator.

\section{Competing Interests}

The authors declare that they have no competing interests.

\section{Authors' Contributions}

GG, GB, KH, AK, FT MA and YB designed the study, analyzed the data, drafted the manuscript and critically reviewed the article.

All authors read and approved the final manuscript. 


\section{References}

[1] Acharya, D. R., Bell, J. S., Simkhada, P., Teijlingen, E. R. and Regmi, P. R. (2010) Women's autonomy in household decision making: Reproductive Health, 7(15) : 7-15

[2] Shireen, J. (1995) Women's education, autonomy and reproductive behavior, experience from developing countries. Oxford: Clarendon Press.

[3] Haile, A. and Enqueselassie, F. (2006) Influence of women's autonomy on couple's contraception use in Jimma town, Ethiopia: Ethiopian Journal of Health Development, 20(3):145-151.

[4] Nguyen, S. (2003) Women's Status and Contraceptive Use. Grey, Egypt.

[5] Deborah, B. (1994) Individual and Community Aspects of Women's Status and Fertility in Rural Banglsdesh: Population Studies, 48(1): 21-45.

[6] Ethiopian Society of Population Studies (2008). Gender inequality and women's empowerment. Addis Ababa: UNFPA,Grey, October 2008.

[7] Central Statistics Authority (2008). The 2007 population and housing census of Ethiopia. Addis Abeba, December, 2008 .
[8] Bogale, B., Wondafrash, M., Tilahun, T. and Girma, E. (2011) Married women's decision making power on modern contraceptive use: BMC Public Health, 11(342) : 1471-2458

[9] Ilene S. and Lisa, C. (2005) Gender Relations and Reproductive Decision Making in Honduras. International Family Planning Perspectives. 31:131-139.

[10] Kinoshita, R. (2003) women's domestic decision-making power and contraceptive use in rural Malawi: International health. Spring 2003, No. 14.

[11] Asya, A. and Mustafa, A. (2004) Women's Autonomy, Education and Employment in Oman and their Influence on Contraceptive Use: Reproductive Health Matters. 12:144154

[12] Govindasamy, P. and Malhotra, A. (1996) Women's position and family planning Stud Fam Plann. 27(6):328-40.

[13] Central Statistical Agency [Ethiopia] and ORC Macro. Ethiopia Demographic and Health Survey. Addis Ababa, Ethiopia and Calverton, Maryland, USA: Central Statistical Agency and ORC Macro 2000.

[14] Michelle, J. (2000) Women's autonomy, women's status and fertility-related behavior in Zimbabwe: Population Research and Policy Review, 19: 255-282. 